\title{
The profound impact of combined severe acidosis and malperfusion on operative mortality in the surgical treatment of type A aortic dissection
}

\author{
Jennifer S. Lawton, MD, ${ }^{\mathrm{a}}$ Marc R. Moon, MD, ${ }^{\mathrm{b}}$ Jingxia Liu, $\mathrm{PhD},{ }^{\mathrm{c}}$ Danielle J. Koerner , BS, ${ }^{\mathrm{b}}$ \\ Kevin Kulshrestha, BS, ${ }^{\mathrm{b}}$ Ralph J. Damiano, Jr, MD, ${ }^{\mathrm{b}}$ Hersh Maniar, MD, ${ }^{\mathrm{b}}$ Akinobu Itoh, MD, ${ }^{\mathrm{b}}$ \\ Keki R. Balsara, MD, ${ }^{b}$ Faraz M. Masood, MD, ${ }^{b}$ Spencer J. Melby, MD, ${ }^{b}$ and Michael K. Pasque, MD $^{b}$
}

\section{ABSTRACT}

Objectives: Surgery for type A aortic dissection is associated with a high operative mortality, and a variety of predictive risk factors have been reported. We hypothesized that a combination of risk factors associated with organ malperfusion and severe acidosis that are not currently documented in databases would be associated with a level of extreme operative risk that would warrant the consideration of treatment paradigms other than immediate ascending aortic surgery.

Methods: Charts of patients undergoing repair of acute type A aortic dissection between January 1, 1996, and May 1, 2016, were queried for preoperative malperfusion, preoperative base deficit, $\mathrm{pH}$, bicarbonate, cardiopulmonary resuscitation, severe aortic insufficiency, redo status, and preoperative intubation. Multivariable logistic analyses were considered to evaluate interested variables and operative mortality.

Results: Between January 1, 1996, and May 1, 2016, 282 patients underwent surgical repair of type A aortic dissection. A total of 66 patients had a calculated base deficit -5 or greater. Eleven of 12 patients $(92 \%)$ with severe acidosis (base deficit $\geq-10$ ) with malperfusion had operative mortality. No patient with severe acidosis with abdominal malperfusion survived. Multivariable analyses identified base deficit, intubation, congestive heart failure, dyslipidemia/statin use, and renal failure as predictors of operative death. The most significant predictor was base deficit -10 or greater (odds ratio, 9.602; 95\% confidence interval, 2.649-34.799).

Conclusions: The combination of severe acidosis (base deficit $\geq-10$ ) with abdominal malperfusion was uniformly fatal. Further research is needed to determine whether the identification of extreme risk warrants consideration of alternate treatment options to address the cause of severe acidosis before ascending aortic procedures. (J Thorac Cardiovasc Surg 2018;155:897-904)

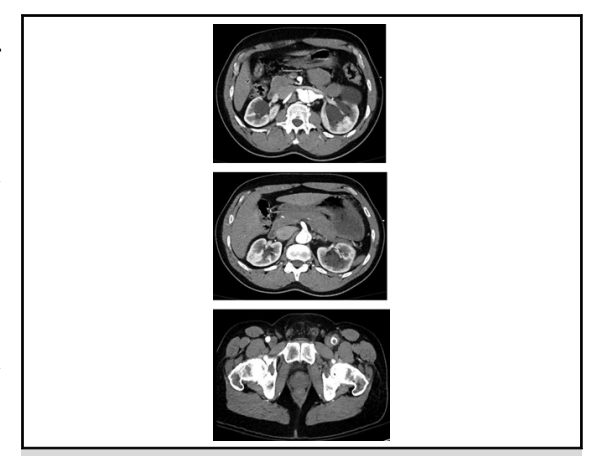

Malperfusion including renal artery, superior mesenteric artery, and left femoral artery.

\section{Central Message}

Significant operative mortality associated with severe acidosis combined with malperfusion warrants consideration of alternate treatment before ascending aortic replacement for type A dissection.

\section{Perspective}

Combined severe acidosis (base deficit $\geq-10$ ) and malperfusion in the present study was associated with operative mortality in $92 \%$ of patients, and no patient with abdominal malperfusion and severe acidosis survived. The objective measurement of base deficit informs decisions regarding the treatment of patients with type A aortic dissection and should be collected in current databases.

See Editorial Commentary page 905
Acute type A aortic dissection is associated with an inhospital mortality rate of $12 \%$ to $35 \% .^{1-7}$ Prompt surgical

\footnotetext{
From the ${ }^{\text {a Division }}$ of Cardiac Surgery, Department of Surgery, Johns Hopkins University, Baltimore, Md; ${ }^{\mathrm{b}}$ Division of Cardiothoracic Surgery, Department of Surgery, and ${ }^{\mathrm{c} D i v i s i o n}$ of Public Health Sciences, Washington University School of Medicine, St Louis, Mo.

Received for publication March 14, 2017; revisions received Oct 15, 2017; accepted for publication Nov 1, 2017; available ahead of print Dec 14, 2017.

Address for reprints: Jennifer S. Lawton, MD, Johns Hopkins University, 1800 Orleans St, Zayed 7107, Baltimore, MD 21287 (E-mail: jlawton4@jhmi.edu). $0022-5223 / \$ 36.00$

Copyright (c) 2017 by The American Association for Thoracic Surgery https://doi.org/10.1016/j.jtcvs.2017.11.002
}

therapy is recommended to prevent the life-threatening complications of rupture of the aorta into the pericardial or pleural space, rupture into a coronary ostium, acute aortic regurgitation, or neurologic compromise. ${ }^{8,9}$ The extent of

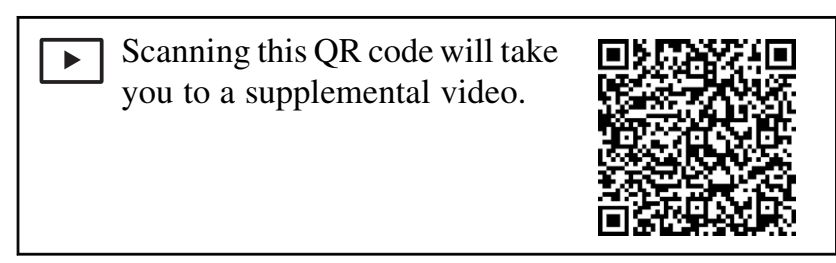




\section{Abbreviations and Acronyms \\ $\mathrm{CHF}=$ congestive heart failure \\ $\mathrm{CPR}=$ cardiopulmonary resuscitation \\ $\mathrm{HCO}_{3}=$ bicarbonate \\ IRAD $=$ International Registry of Aortic Dissection \\ OR $=$ odds ratio \\ STS $=$ Society of Thoracic Surgeons}

the intimal tear is often the entire length of the aorta and jeopardizes blood flow to all organs downstream. The intimal flap may have multiple reentry points, and organs may become malperfused because of flap geometry that may be dynamic over time. The operative treatment and postoperative care consume multiple hospital resources, and the treatment is often referred to aortic centers or large, tertiary centers of care because of these concerns. ${ }^{10-12}$

We hypothesized that a number of preoperative variables not currently collected as part of the International Registry of Aortic Dissection (IRAD) or Society of Thoracic Surgeons (STS) databases, but related to organ malperfusion, would predict operative mortality. Identification of these factors would aid in the creation of algorithms for extremely high-risk patients.

\section{MATERIALS AND METHODS}

The records of all patients who underwent surgery for an acute Stanford type A aortic dissection between January 1, 1996, and May 1, 2016, at one institution with a designated Aortic Center and participation in IRAD were reviewed. Patients with the following characteristics were excluded: intraoperative dissection localized to the ascending aorta, intraoperative retrograde dissection caused by femoral cannulation, subacute or chronic ( $>2$ weeks) type A dissection, and previous type B dissection or aneurysm of the descending aorta including previous repair or stent.

Available patient records were carefully scrutinized for a wide spectrum of preoperative and intraoperative variables. In addition to the usual variables collected for the STS and IRAD databases, records were specifically scrutinized for documented evidence for clinical suspicion of brain, coronary, extremity, or abdominal malperfusion. Additional clinical variables collected included preoperative lowest $\mathrm{pH}$, preoperative lowest bicarbonate $\left(\mathrm{HCO}_{3}\right)$, preoperative nadir base deficit, preoperative cardiopulmonary resuscitation (CPR), redo status, preoperative intubation, and aortic insufficiency. Malperfusion was diagnosed using imaging studies (computed tomography scan with intravenous contrast) and review of records. Findings included the following: neurologic deficit or coma (brain malperfusion), lower-extremity lack of pulse or discoloration and pain (extremity malperfusion), severe abdominal pain (abdominal organ malperfusion), or electrocardiogram evidence of coronary ischemia (coronary malperfusion). Records were surveyed with Washington University Institutional Review Board approval.

Operative technique was variable and largely surgeon dependent and has been described by Lawton and colleagues. ${ }^{5}$ The study end point was operative mortality rate. Operative mortality (30 days) was defined as death in the initial hospitalization or within 30 days of surgery.

\section{Statistics}

Statistical analysis. All statistical tests were 2-sided using an $\alpha=0.05$ level of significance. SAS Version 9.3 (SAS Institute Inc, Cary, NC) was used to perform all statistical analyses.
Descriptive statistics (eg, frequencies, \%, mean, and standard deviation) were completed on preoperative and intraoperative variables. To predict operative mortality, we fitted a multivariable logistic regression model using the patient's preoperative and intraoperative characteristics. Univariate logistic regression model was used to model the binary outcome. Multivariable analysis through stepwise selection was presented to examine the relationship between binary outcome and independent predictors, a significance level of .3 is required to allow a predictor into the model, and a significance level of .15 is required for a predictor to stay in the model. For those selected predictors, additionally, the integrated discrimination improvement was used to assess a model. The macro \%idimacro, which computes integrated discrimination improvement, was used to examine whether a new predictor should be added to a model. The significance of the predictors in the final model was examined by the likelihood ratio test, and the performance of the model was tested by C-statistics. The Hosmer-Lemeshow test was used to test goodness of fit.

Base deficit was included as a single variable and separately as a level ( $\geq 0,-5$ to $0,-10$ to -5 , or $\geq-10$ ). Severe acidosis was defined as base deficit of -10 or greater.

\section{RESULTS}

Between January 1, 1996, and May 1, 2016, 282 patients underwent surgical repair of type A aortic dissection. A total of 51 patients $(18 \%)$ died in the operating room or within the initial hospitalization (operative mortality). A total of 83 patients had an aortic valve procedure (16 valve replacements including 8 root replacement with valve conduits, 8 valve-sparing root replacements, and 59 aortic valve repairs with resuspension of the valve). Table 1 summarizes the clinical characteristics of the patients.

A total of 80 patients $(28 \% ; 80 / 282)$ had malperfusion of any type or a combination of types. Of those 80 patients with malperfusion of any type, $29(36 \%, 29 / 80)$ died (operative mortality) and $51(64 \%, 51 / 80)$ did not. In contrast, only $11 \%(22 / 202)$ of patients who did not have malperfusion died (operative mortality). Operative mortality was significantly higher in the group of patients with malperfusion than in patients with no malperfusion $(29 / 80,36 \%$ vs 22/202, 11\%, respectively, $P<.001$ ).

A total of 66 patients had a calculated base deficit -5 or greater (Table 2). Of these patients, 42 had a base deficit between -5 and -10 , and 24 had a base deficit -10 or greater. Eleven patients $(26 \%, 11 / 42)$ with a base deficit -5 to -10 had operative mortality, and 11 patients $(46 \%, 11 / 24)$ with severe acidosis (base deficit $\geq-10$ ) had operative mortality.

Twenty-one patients had a combination of base deficit -5 to -10 and malperfusion. Ten of 21 patients $(48 \%)$ with base deficit -5 to -10 combined with malperfusion of any type died (operative mortality). Among these 21 patients, malperfusion was associated with $29 \%, 33 \%$, $50 \%, 60 \%$, or $75 \%$ operative mortality depending on the type: extremity only, brain only, abdominal only, abdominal + extremity, or coronary only, respectively.

Twelve patients had a combination of severe acidosis (base deficit $\geq-10$ ) and malperfusion. Eleven of 12 patients $(92 \%)$ with severe acidosis combined with malperfusion of any type died (operative mortality). Operative mortality in 
TABLE 1. Patient characteristics of 282 patients who underwent surgery for acute type $A$ aortic dissection

\begin{tabular}{|c|c|}
\hline Variable & $\mathbf{N}=\mathbf{2 8 2}$ \\
\hline \multicolumn{2}{|l|}{ Age, y $(\%)$} \\
\hline $18-39$ & $29(10.3)$ \\
\hline $40-69$ & $176(62.4)$ \\
\hline $70-79$ & $51(18.1)$ \\
\hline $80+$ & $26(9.2)$ \\
\hline Male $(\%)$ & $165(58.5)$ \\
\hline \multicolumn{2}{|l|}{ White $(\%)^{*}$} \\
\hline Yes & $198(70.5)$ \\
\hline No & $83(29.5)$ \\
\hline \multicolumn{2}{|l|}{ Year of surgery range } \\
\hline $1996-2000$ & $43(15.3)$ \\
\hline 2001-2005 & $43(15.3)$ \\
\hline 2006-2009 & $64(22.7)$ \\
\hline 2010-2014 & $120(42.6)$ \\
\hline 2015 & $12(4.3)$ \\
\hline \multicolumn{2}{|l|}{ Height range, cm (\%) } \\
\hline $140-160$ & $41(14.5)$ \\
\hline $161-180$ & $163(57.8)$ \\
\hline $181-200$ & 75 (26.6) \\
\hline $200+$ & $3(1.1)$ \\
\hline \multicolumn{2}{|l|}{ Weight range, $\mathrm{kg}(\%)$} \\
\hline $38-69$ & $55(19.5)$ \\
\hline $70-100$ & $161(57.1)$ \\
\hline $101-130$ & $49(17.4)$ \\
\hline $131+$ & $17(6.0)$ \\
\hline Previous MI (\%) & $41(14.5)$ \\
\hline CHF $(\%)$ & $32(11.4)$ \\
\hline \multicolumn{2}{|l|}{ NYHA (\%) } \\
\hline No CHF & $152(53.9)$ \\
\hline I & $56(19.9)$ \\
\hline II & $13(4.6)$ \\
\hline III & $21(7.5)$ \\
\hline IV & $40(14.2)$ \\
\hline Cardiogenic shock (\%) & $179(63.5)$ \\
\hline Smoker $(\%)$ & $153(54.3)$ \\
\hline Diabetes $(\%)$ & $31(11.0)$ \\
\hline \multicolumn{2}{|l|}{ Dyslipidemia/statin use (\%) } \\
\hline Yes & $104(36.9)$ \\
\hline No & $177(62.8)$ \\
\hline Unknown & $1(0.4)$ \\
\hline Renal failure $(\%)$ & $29(10.3)$ \\
\hline \multicolumn{2}{|l|}{ Dialysis $(\%)^{*}$} \\
\hline Yes & $7(3.5)$ \\
\hline No & $194(96.5)$ \\
\hline Hypertension (\%) & $228(80.9)$ \\
\hline \multicolumn{2}{|l|}{ Chronic lung disease $(\%)$} \\
\hline None & $242(85.8)$ \\
\hline Mild, moderate, or severe & $39(13.8)$ \\
\hline Unknown & $1(0.4)$ \\
\hline
\end{tabular}

TABLE 1. Continued

\begin{tabular}{lc}
\hline \multicolumn{1}{c}{ Variable } & $\mathbf{N}=\mathbf{2 8 2}$ \\
\hline Immunosuppression (\%) & $10(3.6)$ \\
PVD (\%) & $31(11.0)$ \\
CVD $(\%)$ & $52(18.4)$ \\
CVA (\%)* & \\
Yes & $40(29.4)$ \\
No & $96(70.6)$ \\
TIA $(\%)^{*}$ & \\
Yes & $6(11.8)$ \\
No & $45(88.2)$
\end{tabular}

Previous cardiac surgery $(\%)^{*}$

Yes $3(10.0)$

No $27(90.0)$

Ejection fraction range $(\%)^{*}$

20-29 $4(2.6)$

$30-39$

40-49 $21(13.4)$

$50+\quad 123(78.3)$

Statin use $(\%)^{*}$

Yes $\quad 177(63.0)$

No 104 (37.0)

Aortic insufficiency $(\%)^{*}$

None $\quad 50$ (22.9)

Mild/trivial 74 (33.9)

Moderate 48 (22.0)

Severe $44(20.2)$

Not documented $2(0.9)$

Mitral insufficiency $(\%)^{*}$

None $\quad 81(41.8)$

Mild/trivial 96 (49.5)

Moderate $10(5.2)$

Severe 5 (2.6)

Not documented $2(1.0)$

Malperfusion brain (\%) $22(7.8)$

Malperfusion extremity (\%) 49 (17.4)

Malperfusion abdominal organs (\%) 25 (8.9)

Malperfusion coronary (\%) $7(2.5)$

$\mathrm{pH}(\mathrm{n}$, mean $\pm \mathrm{SD}) \quad 266,7.3 \pm 0.1$

$\mathrm{HCO}_{3}(\mathrm{n}$, mean $\pm \mathrm{SD}) \quad 266,23.2 \pm 4.8$

Base deficit ( $\mathrm{n}$, mean $\pm \mathrm{SD}) \quad 266,-2.0 \pm 5.6$

CPR (\%) $11(3.9)$

Redo (\%) $18(6.4)$

Intubated (\%) 40 (14.2)

Crossclamp time (n, mean \pm SD) $\quad 273,92.3 \pm 39.4$

Perfusion time range (min)

$\begin{array}{ll}22-100 & 29(10.3) \\ 101-150 & 73(25.9) \\ 151-200 & 93(33.0) \\ 201+ & 87(30.9)\end{array}$

(Continued) 
TABLE 1. Continued

\begin{tabular}{lc}
\hline \multicolumn{1}{c}{ Variable } & $\mathbf{N}=\mathbf{2 8 2}$ \\
\hline Lowest temperature $(\mathrm{n}$, mean $\pm \mathrm{SD})$ & $282,26.6 \pm 10.5$ \\
Base deficit*, $\dagger$ & \\
$\geq-10$ & $24(9.0)$ \\
-10 to -5 & $42(15.8)$ \\
-5 to 0 & $95(35.7)$ \\
$\geq 0$ & $105(39.5)$ \\
\hline
\end{tabular}

Resuscitation was requirement for CPR within 1 hour of operative procedure. $M I$, Myocardial infarction; $C H F$, congestive heart failure; NYHA, New York Heart Association; $P V D$, peripheral vascular disease; $C V D$, cardiovascular disease; $C V A$, cerebrovascular accident; TIA, transient ischemic attack; $S D$, standard deviation; $\mathrm{HCO}_{3}$, bicarbonate; $\mathrm{CPR}$, cardiopulmonary resuscitation. *The denominator for the percentages is the sum of patients across all categories, excluding missing values. $\dagger$ Base deficit $\geq-10$ implies a greater deficit (larger number) than 10, although the numeric value is actually less than -10 .

this group (base deficit $\geq-10$ with malperfusion) was statistically greater than operative mortality in the group of patients with base deficit -5 to -10 and malperfusion (11/12 [92\%] vs 10/21 [48\%], respectively; $P=.022$ ). Among these 12 patients, malperfusion was associated with $50 \%$ mortality in the extremity only type and $100 \%$ mortality in all other types (brain only, coronary only, abdominal only, abdominal + extremity, and abdominal + extremity + brain). An ominous trend of increasing mortality was noted with the degree of preoperative acidosis in patients with any abdominal malperfusion (Table 3).

A statistically significant difference was also noted when comparing operative mortality in the 33 patients with base deficit lf -5 or greater and malperfusion with 43 patients with base deficit between 0 and -5 and malperfusion (21/ $33,64 \%$ vs $7 / 43,16 \%, P<.0001)$.

Univariable analysis identified the following factors associated with operative mortality after surgery for acute type A aortic dissection: malperfusion brain, malperfusion extremity, malperfusion coronary, malperfusion abdomen, preoperative lowest $\mathrm{pH}$, preoperative lowest $\mathrm{HCO}_{3}$, preoperative nadir base deficit, preoperative CPR, preoperative intubation, preoperative New York Heart Association class, preoperative dyslipidemia/statin use, preoperative renal failure, and preoperative mitral insufficiency.

Multivariable analysis through stepwise selection demonstrated 5 factors associated with operative mortality

TABLE 2. Mortality in patients with base deficit -5 or Greater $(\mathbf{N}=66)$

\begin{tabular}{lcc}
\hline & $\begin{array}{c}\text { Malperfusion } \\
(\mathbf{N}=\mathbf{3 3})\end{array}$ & $\begin{array}{c}\text { No malperfusion } \\
(\mathbf{N}=\mathbf{3 3})\end{array}$ \\
\hline $\begin{array}{c}\text { Base deficit }-5 \text { to }-10 \\
(\mathrm{~N}=42)\end{array}$ & 21 & 21 \\
Operative death $(\mathrm{N}=11)$ & $10(10 / 21,48 \%)$ & $1(1 / 21,5 \%)$ \\
Base deficit $\geq-10(\mathrm{~N}=24) *$ & 12 & 12 \\
Operative death $(\mathrm{N}=11)$ & $11(11 / 12,92 \%) \dagger$ & $0(0 / 12,0 \%)$ \\
\hline *Base deficit $\geq-10$ implies a greater deficit (larger number) than 10, even though the \\
numeric value is actually less than $-10 . \dagger P<.05$ versus operative death in base deficit \\
-5 to -10 with malperfusion group.
\end{tabular}

TABLE 3. Increasing operative mortality in patients with increasing base deficit and abdominal malperfusion

\begin{tabular}{lc}
\hline Base deficit & Operative mortality \\
\hline 0 to -5 & $0 \%(0 / 7)$ \\
-5 to -7 & $33 \%(1 / 3)$ \\
-7 to -10 & $75 \%(3 / 4)$ \\
$\geq-10 *$ & $100 \%(7 / 7)$ \\
\hline
\end{tabular}

*Base deficit $\geq-10$ implies a greater deficit (larger number) than 10, although the numeric value is actually less than -10 .

after surgery for acute type A aortic dissection: preoperative nadir base deficit $(P=.0059)$, preoperative intubation, preoperative congestive heart failure (CHF), preoperative dyslipidemia/statin use, and preoperative renal failure (Table 4). The final model included 51 events. C-statistic was 0.798 , and $P$ value from Hosmer-Lemeshow test was .73 (chi-square 3.60 , degrees of freedom $=6$ ) in the final model (Video 1).

The odds of operative mortality for base deficit -10 or greater over the odds for base deficit 0 or greater was 9.602 (2.649-34.799). Patients with base deficit -10 or greater have at least a $164.9 \%$ increase in the odds of operative mortality than the patients with base deficit 0 or less. The odds of operative mortality for base deficit -5 to -10 and for 0 to -5 over the odds for base deficit of 0 or greater were 4.153 (1.337-12.904) and 3.670 (1.348-9.993), respectively. Likewise, the odds of operative mortality was significantly increased for patients with preoperative intubation (odds ratio [OR], 3.752; 1.602-8.785), preoperative CHF (OR, 3.701; 1.289-10.630), preoperative dyslipidemia/statin use (OR, 2.736; 1.193-6.272), and preoperative renal failure (OR, 3.592; 1.377-9.373), respectively.

\section{DISCUSSION}

The treatment of acute type A aortic dissection remains complicated and requires multidisciplinary teams. Although operative mortality after repair of type A aortic dissection has decreased over the last decade in the United States, it remains high $(12 \%-35 \%) \cdot{ }^{1-7}$ No randomized trials evaluating treatment methods or comparing operative techniques have been conducted, and treatment decisions are based largely on retrospective studies and proposed algorithms based on readily available databases (IRAD, German registry, or STS). These databases have not included the variable of preoperative acidosis (with or without organ malperfusion), which is a marker of severe malperfusion or shock. ${ }^{13-20}$ Operative mortality after repair of type A aortic dissection is significantly affected by the presence of organ malperfusion (Figure 1), which is manifested as acidosis and captured in the base excess calculation in the present study.

Malperfusion and preoperative acidosis have been individually implicated as predictors of increased operative 
TABLE 4. Multivariable predictors of operative mortality

\begin{tabular}{lcccr}
\hline & \multicolumn{4}{c}{ Multivariable } \\
\cline { 2 - 5 } & P value & OR & 95\% CI \\
\hline Base deficit & .0059 & & & \\
$\geq-10$ vs $\geq 0$ & & 9.602 & 2.649 & 34.799 \\
-5 to -10 vs $\geq 0$ & & 4.153 & 1.337 & 12.904 \\
0 to -5 vs $\geq 0$ & & 3.670 & 1.348 & 9.993 \\
Intubated (yes vs no) & .0023 & 3.752 & 1.602 & 8.785 \\
CHF (yes vs no) & .0150 & 3.701 & 1.289 & 10.630 \\
Statin use (yes vs no) & .0174 & 2.736 & 1.193 & 6.272 \\
Renal failure (yes vs no) & .0090 & 3.592 & 1.377 & 9.373 \\
\hline
\end{tabular}

Variables considered included malperfusion brain, malperfusion extremity, malperfusion abdomen, malperfusion coronary, $\mathrm{pH}, \mathrm{HCO}$, base deficit, CPR, redo, intubation, sex, race, height, weight, year of surgery, previous myocardial infarction, CHF, New York Heart Association class, cardiogenic shock, beta-blocker use, medication nitroglycerin intravenously, anticoagulant, Coumadin, inotropic use, aspirin use, smoking status, history of coronary artery disease, diabetes, dyslipidemia/statin use, renal failure, hypertension, chronic lung disease, peripheral vascular disease, cardiovascular disease, previous cardiovascular surgery, use of crossclamp, use of deep hypothermic circulatory arrest, reperfusion direction, age, surgeon, crossclamp time, surgical repair type, $\mathrm{CPB}$ time, and lowest temperature. $\mathrm{OR}$, Odds ratio; $\mathrm{CI}$, confidence interval; $C H F$, congestive heart failure.

mortality in patients undergoing surgery for type A aortic dissection. ${ }^{13,14,16,18,21}$ In a study of 96 patients with malperfusion and acute type A aortic dissection, Grimm and colleagues ${ }^{13}$ noted variable mortality depending on organ malperfusion $(7 \%$ extremity, $10 \%$ renal, $20 \%$ brain, and $100 \%$ intestinal); however, base deficit or acidosis was not measured. ${ }^{13}$ In a recent study of 144 patients with type A aortic dissection, Bennett and colleagues ${ }^{21}$ correlated preoperative lactic acidosis and operative mortality. The current study uniquely stratified operative mortality in the presence of organ malperfusion depending on the degree of base deficit. Severe acidosis (base deficit $\geq-10$ ) was uniformly fatal in patients with brain only, coronary only, abdominal only, abdominal + extremity, and abdominal + extremity + brain malperfusion. Only patients with isolated extremity malperfusion and severe acidosis

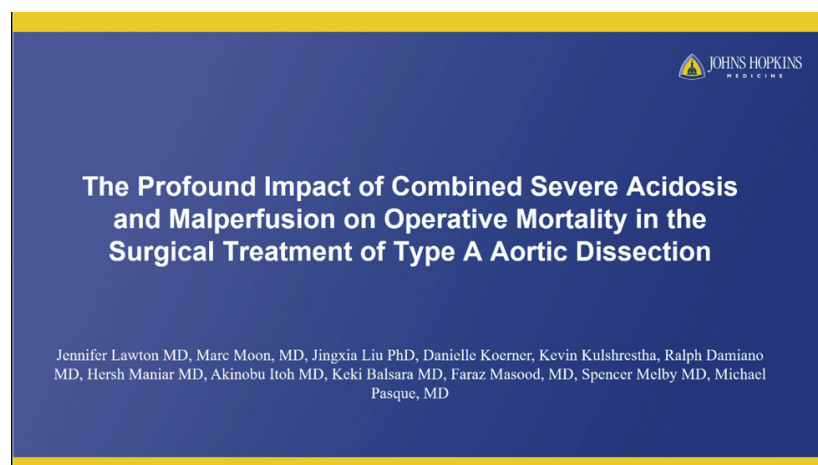

VIDEO 1. Dr Jennifer Lawton discusses results, importance, and relevance of the article. Video available at: http://www.jtcvsonline.org/ article/S0022-5223(17)32428-5/fulltext.
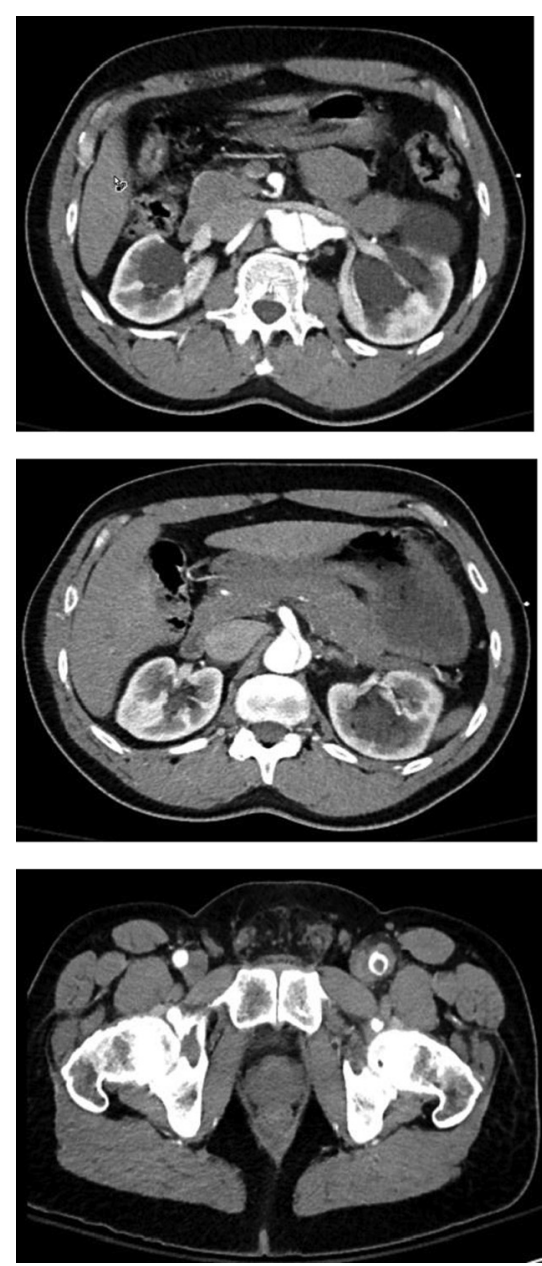

FIGURE 1. Type A aortic dissection flap with malperfusion on computed tomography scan. Right renal supplied by true lumen (top), superior mesenteric artery false lumen (middle), and false lumen with thrombus in left femoral artery (bottom).

survived. Malperfusion with base deficit -5 or greater was also associated with increasing mortality $(0 \%-100 \%)$ depending on the type.

Malperfusion (brain, extremity, coronary, or abdomen), preoperative lowest $\mathrm{pH}$, preoperative lowest $\mathrm{HCO}_{3}$, preoperative nadir base deficit, preoperative $\mathrm{CPR}$, preoperative intubation, preoperative New York Heart Association class, preoperative dyslipidemia, preoperative renal failure, and preoperative mitral insufficiency were found by univariable analysis to be associated with operative mortality in the present study. Others have reported age, CPR, preoperative ventilation, inotropic support, malperfusion syndrome (coronary, visceral, or extremity), coronary artery disease, critical preoperative state (defined as presence of inotropic support, CPR, or mechanical ventilation), dialysis or renal failure, and reoperation as predictors of operative mortality. ${ }^{16,20,22-25}$ Of note, dyslipidemia/statin use has not been identified as a factor associated with operative mortality 


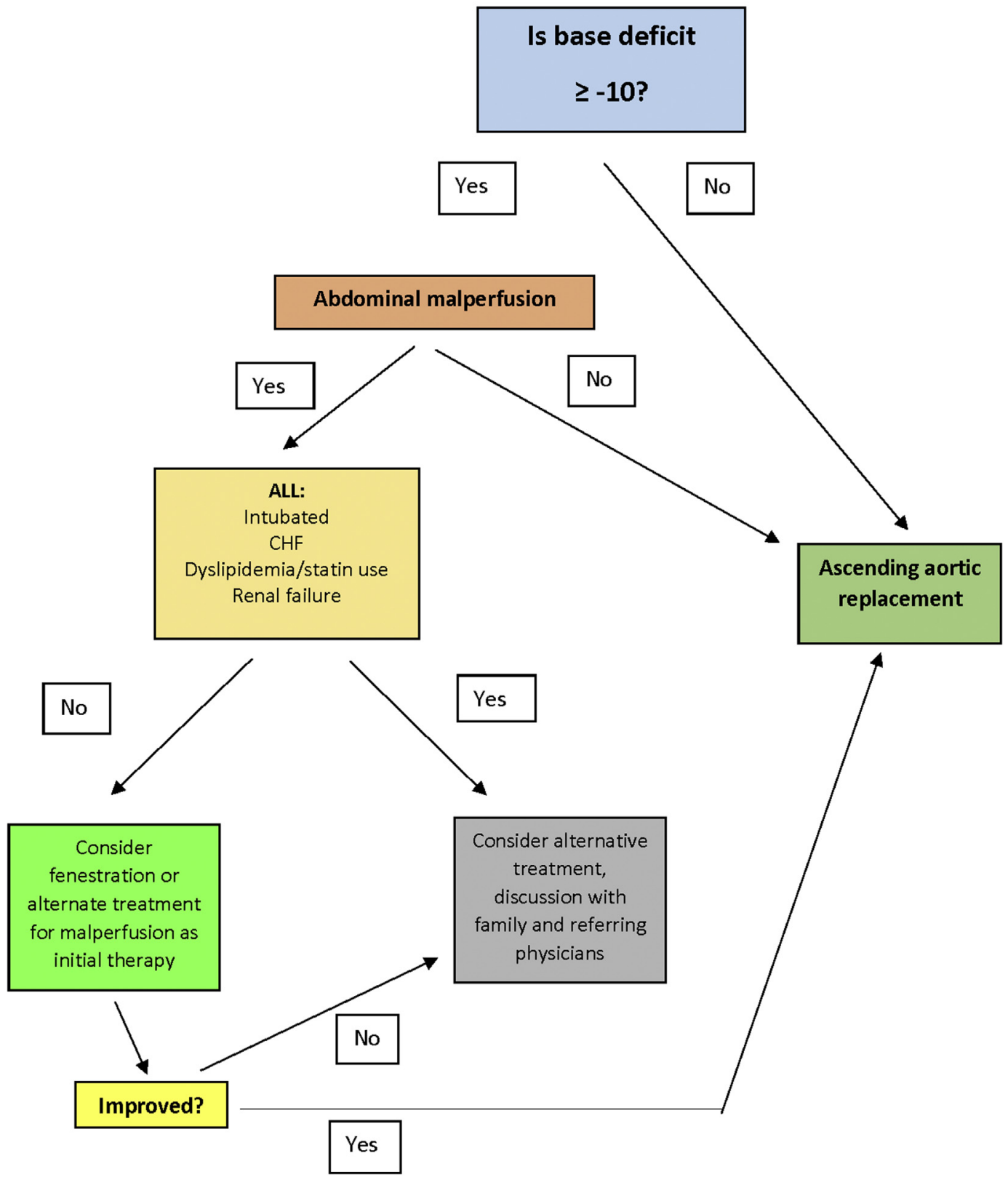

FIGURE 2. Proposed algorithm for the treatment of acute type A aortic dissection. The algorithm depicted is one proposed method to consider treatment options in patients with acute type A aortic dissection. $\mathrm{CHF}$, Congestive heart failure.

and acidosis or base deficit has not been evaluated as a variable. $^{16,22}$

Five factors were identified by multivariable analysis in the present study as associated with operative mortality: base deficit, intubation, $\mathrm{CHF}$, dyslipidemia, and renal failure. Preoperative intubation and renal failure have been reported by many investigators as independent predictors of operative mortality and intuitively indicate a poor preoperative status. $^{16,26}$ Likewise, history of $\mathrm{CHF}$ and renal failure at the time of emergency surgery are indicative of a complicated course and less optimal preoperative state. $^{12,17}$ Of note, shock and CPR were not found to be 
predictors of operative mortality in the current study. In the current study, 11 patients had CPR at some time before or on arrival to the operating room. Five of these patients had operative mortality within 1 day, 1 survived for 5 days, and the remaining 5 survived for a range of 881 to 3074 days. In patients deemed to have shock $(\mathrm{N}=179)$, 37 died $(20.6 \%)$ within 66 days and 20 had abdominal malperfusion, whereas 14 of 103 patients with no shock $(13.6 \%)$ died and only 2 had abdominal malperfusion. We propose that shock and CPR are less objective indicators (because of diagnostic definitions and coding inconsistencies) of poor clinical prognosis when compared with laboratory values indicating acidosis, such as those used to calculate base deficit.

Preoperative dyslipidemia, or statin use, has not been reported before as a predictor of operative mortality in patients with acute type A aortic dissection. The reasons for this finding are unknown, and the finding is counterintuitive to current knowledge of reduced risk of aortic aneurysm growth and poor outcomes in patients not taking statin medications. This finding requires further investigation.

Preoperative base deficit suggests organ malperfusion or a shock state. Base deficit and level of acidosis are not currently collected as variables for common databases. In the current study, base deficit (particularly in the severe acidosis category) was the strongest predictor of operative mortality, and it is a variable that is simple and easy to document and use at the bedside. In addition, acidosis is a direct quantitative measurement of organ ischemia and injury, unlike the variable of malperfusion, which may be less objective and is often based on physical examination findings or symptoms of pain. The findings in the current study suggest added benefit to the inclusion of these variables in modern aortic dissection databases.

Malperfusion has been documented to occur in approximately $30 \%$ of acute type A aortic dissection cases (consistent with the present study). Delayed ascending aortic surgery has been suggested by others in the setting of malperfusion $^{19,27-29}$ despite the fact that reestablishing the true lumen by ascending aortic replacement often resolves the malperfusion. Deeb and colleagues ${ }^{29}$ suggest delay in aortic treatment until recovery from end-organ injury associated with malperfusion and that resultant reperfusion injury and pulmonary dysfunction often improve with medical management. They noted only 1 death $(5 \%)$ in a group of 20 patients who had delay of aortic surgery, that a delay in aortic surgery was the only independent variable predictive of outcome, and that the likelihood of death in patients with an acute type A dissection complicated by malperfusion is 33 times greater if they undergo immediate surgical repair compared to a delay. ${ }^{29}$ Vallabhajosyula and colleagues ${ }^{30}$ suggested adding concomitant antegrade thoracic endovascular aortic repair to hemiarch replacement in patients with DeBakey type 1 aortic dissection in the presence of malperfusion. ${ }^{30}$ Delay in the treatment of the ascending aorta is hard to justify given the known mortality of an acute type A aortic dissection within the first 48 hours. However, important predictors of operative mortality, such as base deficit with abdominal malperfusion, may aid in these diagnostic and treatment decisions. The important and ominous finding in the current study that $100 \%$ of patients with abdominal malperfusion and severe acidosis died suggests that the serious consideration of alternative treatment strategies aimed at directly addressing the malperfusion as a critical first step is warranted. An algorithm for alternative treatment of patients with acute type A aortic dissection is proposed on the basis of these findings (Figure 2). The algorithm includes consideration for catheter-based or surgical fenestration concomitant with correction of acid-base abnormalities before ascending aortic replacement in these patients. This ideally could be performed in a hybrid operating room just before ascending aortic replacement to minimize risk of delay in addressing the ascending aorta. Likewise, in patients with severe acidosis, abdominal malperfusion, and other identified clinical risk factors (respiratory failure requiring intubation, CHF, and renal failure), consideration for limited surgical intervention and family discussion may be appropriate initially. The combined detrimental effects of acidosis and malperfusion and the implications for operative mortality during the repair of acute type A aortic dissection are evident in the data presented in Tables 2 and 3, and these data may aid in such discussions. The data derived from this study thus allow for a clinically relevant predictive model of operative mortality. Such a model will require validation for confirmation of its clinical usefulness.

\section{Study Limitations}

The present study is limited because it is a retrospective, single-center study with a variety of surgical strategies and surgeons. Detailed data are lacking in the preoperative and postoperative treatment of malperfusion in patients; however, it was customary for patients with acute type A aortic dissection to be treated primarily with aortic replacement during the study period. The conclusions are not intended to deny treatment or to suggest futility in the treatment of any subset of patients with acute type A aortic dissection.

\section{CONCLUSIONS}

The restoration of a true lumen in the dissected aorta with ascending aortic replacement often restores adequate flow to all organs in patients with acute type A aortic dissection. However, malperfusion due to the dissection may not resolve because of the dynamic and unpredictable nature of an intimal flap, resulting in continued malperfusion of any organ. Because of the dismal prognosis of patients with abdominal malperfusion and severe acidosis, alternative treatment algorithms may be appropriate before ascending aortic replacement in some patients. 


\section{Conflict of Interest Statement}

Authors have nothing to disclose with regard to commercial support.

The authors thank Tina Burmeister and Patricia Buckley for data collection and analysis.

\section{References}

1. Moon MR, Sundt TM, Pasque MK, Barner HB, Huddleston CB, Damiano RJ, et al. Does the extent of proximal or distal resection influence outcome for type A dissections? Ann Thorac Surg. 2001;71:1244-50.

2. Zierer A, Moon MR, Melby SJ, Moazami N, Lawton JS, Kouchoukos NT, et al. Impact of perfusion strategy on neurologic recovery in acute type A aortic dissection. Ann Thorac Surg. 2007:83:2122-9.

3. Lai DT, Robbins RC, Mitchell S, Moore KA, Oyer PE, Shumway NE, et al. Does profound hypothermic circulatory arrest improve survival in patients with acute type A aortic dissection? Circulation. 2002;106:I218-28.

4. Chiappini B, Schepens M, Tan E, Dell'Amore A, Morshuis W, Dossche K, et al. Early and late outcomes of acute type A aortic dissection: analysis of risk factors in 487 consecutive patients. Eur Heart J. 2005;26:180-6.

5. Lawton JS, Liu J, Kulshrestha K, Moon MR, Damiano RJ, Maniar H, et al. The impact of surgical strategy on survival following repair of type A aortic dissection. J Thorac Cardiovasc Surg. 2015;150:294-301.

6. Mehta RH, Suzuki T, Hagan PG, Bossone E, Gilon D, Llovet A, et al; on behalf of the IRAD investigators. Predicting death in patients with acute type A aortic dissection. Circulation. 2002;105:200-6.

7. Mody PS, Wang Y, Geirsson A, Kim N, Desai MM, Gupta A, et al. Trends in aortic dissection hospitalizations, interventions, and outcomes among Medicare beneficiaries in the United States, 2000-2011. Circ Cardiovasc Oual Outcomes. 2014; 7:920-8.

8. Isselbacher EM. Diseases of the aorta. In: Zipes DP, Libby P, Bonow RO, Braunwald E, eds. Braunwald's Heart Disease: A Textbook of Cardiovascular Medicine. 7th ed. Philadelphia: Elsevier Saunders; 2001:1425.

9. Green GR, Kron IL. Aortic dissection. In: Cohn LH, Edmunds LH, eds. Cardiac Surgery in the Adult. New York: McGraw-Hill; 2003:1106.

10. Bonser RS, Ranasinghe AM, Loubani M, Evans JD, Thalji NMA, Bachet JE, et al. Evidence, lack of evidence, controversy, and debate in the provision and performance of the surgery of acute type A aortic dissection. J Am Coll Cardiol. 2011;58:2455-74.

11. Chikwe J, Cavallaro P, Itagaki S, Seigerman M, DiLuozzo G, Adams DH. National outcomes in acute aortic dissection: influence of surgeon and institutional volume on operative mortality. Ann Thorac Surg. 2013;95:1563-9.

12. Goodwin AT, Ooi A, Kitcat J, Nashef SA. Outcomes in emergency redo cardiac surgery: cost, benefit and risk assessment. Interact Cardiovasc Thorac Surg. 2003;2:227-30

13. Grimm JC, Magruder JT, Crawford TC, Sciortino CM, Zehr KJ, Mandal K, et al Differential outcomes of type A dissection with malperfusion according to affected organ system. Ann Cardiothorac Surg. 2016;5:202-8.

14. Afifi RO, Sandh HK, Leake SS, Rice RD, Azizzadeh A, Charlton-Ouw KM, et al. Determinants of operative mortality in patients with ruptured acute type A aortic dissection. Ann Thorac Surg. 2016;101:64-71.

15. Czerny M, Schoenhoff F, Etz C, Englberger L, Khaladj N, Zierer A, et al. The impact of pre-operative malperfusion on outcome in acute type A aortic dissection. J Am Coll Cardiol. 2015;65:2628-35.
16. Leontyev S, Legare J, Borger MA, Buth KJ, Funkat AK, Gerhard J, et al. Creation of a scorecard to predict in-hospital death in patients undergoing operations for acute type A aortic dissection. Ann Thorac Surg. 2016;101:1700-6.

17. Rampoldi V, Trimarchi S, Eagle KA, Nienaber CA, Oh JK, Bossone E, et al. Simple risk models to predict surgical mortality in acute type A aortic dissection: The International Registry of Acute Aortic Dissection Score. Ann Thorac Surg. 2007; $83: 55-61$.

18. Di Eusaniao M, Trimarchi S, Patel HJ, Hutchison S, Suzuki T, Peterson MD, et al Clinical presentation, management, and short-term outcome of patients with type A acute dissection complicated by mesenteric malperfusion: observations from the International Registry of Acute Aortic Dissection. J Thorac Cardiovasc Surg. 2013;145:385-90.

19. Perera NK, Galvin SD, Seevanayagam S, Matalanis G. Optimal management of acute type A aortic dissection with mesenteric malperfusion. Interact Cardiovasc Thorac Surg. 2014;19:290-4.

20. Santini F, Montalbano G, Casali G, Messina A, Iafrancesco M, Luciani GB, et al Clinical presentation is the main predictor of in-hospital death for patients with acute type A aortic dissection admitted for surgical treatment: a 25 years experience. Int J Cardiol. 2007:115:305-11.

21. Bennett JM, Wise ES, Hocking KM, Brophy CM, Eagle SS. Hyperlactemia predicts surgical mortality in patients presenting with acute Stanford type-A aortic dissection. J Cardiothorac Vasc Anesth. 2017;31:54-60.

22. Klodell CT, Karimi A, Beaver TM, Hess PJ, Martin TD. Outcomes for acute type A aortic dissection: effects of previous cardiac surgery. Ann Thorac Surg. 2012; 93:1206-12.

23. Hata M, Shiono M, Inoue T, Sezai A, Niino T, Funahashi M, et al. Preoperative cardiopulmonary resuscitation is the only predictor for operative mortality of type A acute aortic dissection: a recent 8-year experience. Ann Thorac Cardiovasc Surg. 2004;10:101-5.

24. Pacini D, Leone A, Belotti LM, Fortuna D, Gabbieri D, Zussa C, et al. Acute type A aortic dissection: significance of multiorgan malperfusion. Eur J Cardiothorac Surg. 2013;43:820-6.

25. Geirsson A, Szeto WY, Pochettino A, McGarvey ML, Keane MG, Woo WJ, et al Significance of malperfusion syndromes prior to contemporary surgical repair fo acute type A dissection: outcomes and need for additional revascularizations. Eur J Cardiothorac Surg. 2007:32:255-62.

26. Conzelmann LO, Weigang E, Mehlhorn U, Abugameh A, Hoffman I, Blettner M et al; on behalf of the GERAADA Investigators. Mortality in patients with acute aortic dissection type A: analysis of pre- and intraoperative risk factors from the German Registry for acute aortic dissection type A. Eur J Cardiothorac Surg. 2016;49:e44-52.

27. Girdauskas E, Kuntze T, Borger MA, Falk V, Mohr FW. Surgical risk of preoperative malperfusion in acute type A aortic dissection. J Thorac Cardiovasc Surg. 2009; 138:1363-9.

28. Patel HJ, Williams DM, Dasika NL, Suzuki Y, Deeb GM. Operative delay for peripheral malperfusion syndrome in acute type A aortic dissection: a long-term analysis. J Thorac Cardiovasc Surg. 2008;135:1288-95.

29. Deeb GM, Williams DM, Bolling SF, Quint LE, Monaghan H, Sievers J, et al Surgical delay for acute type A dissection with malperfusion. Ann Thorac Surg. 1997;64:1669-75.

30. Vallabhajosyula P, Gottret JP, Menon R, Sultan I, Abbas Z, Siki M, et al. Central repair with antegrade TEVAR for malperfusion syndromes in acute Debakey 1 aortic dissection. Ann Thorac Surg. 2017;103:748-55.

Key Words: aorta, aortic dissection adult cardiac, operative mortality, malperfusion, acidosis 